\title{
Designing sustainable and responsible wine tourism experiences
}

\author{
S. Filopoulos and N. Frittella \\ Wine in Moderation (WiM) Association, Avenue des Arts 43, 1040 Brussels, Belgium
}

\begin{abstract}
Wine tourism involves a wide ecosystem of actors. It is not only a source of revenue for wine regions, for the wine business value chain and for local societies, but it can also reveal and safeguard the cultural heritage of wine and support wine regions sustainability. Wine in Moderation - Art de Vivre is an international programme of the wine sector for a sustainable wine culture looking to inspire well-being and contribute to the reduction of alcohol related harm. The article recognises the opportunity which arises through wine tourism, to introduce the visitor directly to wine culture and to educate him on how to best appreciate wine in moderation and responsibly, while looking to present activities and sustainable wine tourism business models that place sensible consumption in the design of their visitor experience. The article takes into consideration current consumer, policy and business trends, principles of sustainable business models, design thinking and systems' theory, and good practices developed in the framework of the 10 years of the Wine in Moderation programme, to understand how to develop a sustainable wine tourism experience and help create and capture value for wineries, local communities and the wider wine tourism ecosystem. Sustainable wine tourism is an opportunity for growth for the wine value chain. Organising better the visiting areas and offering choices to the guest to experience wine responsibly will prove beneficial both for operators and visitors. Co-creation can provide solutions and far more services which visitors would be willing to experience and pay for. In a growing wine tourism market, wineries and related actors should be fit for purpose, creative and open for partnerships. Adapting a systemic approach, transforming and expanding current business model will be necessary to fully capitalise on the potential of more open and sustainable societies and economies.
\end{abstract}

\section{Introduction}

\subsection{Sustainable wine tourism in the international political environment}

Wine tourism has been part of the wine business for a significant period and can be considered today as one of the most flourishing tourism segments [1].

Wine tourism has gained traction both in the wine and the tourism value chain as well as among authorities and academia. In 2016, the United Nation World Tourism Organisation (UNWTO) organised the $1^{\text {st }}$ UNWTO Global Conference on Wine Tourism in Georgia and published the Georgia Declaration on Wine Tourism [2]. The declaration set the framework for Wine Tourism in the institutional environment of the UNWTO, recognising wine tourism as part of Gastronomy and Cultural Tourism and "as a key element for both emerging and mature tourism destinations in which tourists can experience the culture and lifestyle of destinations while fostering sustainable tourism development" [2]. The two consequent annual conferences that followed, continued to work on the sustainable development of wine tourism, leading the $3^{\text {rd }}$ edition to focus on "Wine Tourism as a Tool for Rural Development" stressing the contribution of tourism to the 2030 Agenda for Sustainable Development and the 17 Sustainable Development Goals (SDGs). The conclusions of the $3^{\text {rd }}$ global conference highlight the need for partnership and innovative models of collaboration as well as local-community engagement and empowerment.

\subsection{The United Nations' 2030 agenda for sustainable development}

The 2030 Agenda for Sustainable Development and the (SDGs), were adopted in the 2015 United Nations (UN) Summit and build on the Millennium Development Goals (MDGs). The 17 SDGs have 169 targets and 304 indicators that will measure compliance. Nonetheless, the SDGs are interlinked and should not only be seen at individual level. The SDG number 3 Good Health and Well-Being sets among others the target to "Strengthen the prevention and treatment of substance abuse, including narcotic drug abuse and harmful use of alcohol".

The harmful use of alcohol is one of the leading risk factors for the population's health worldwide and has a direct impact on many health-related targets of the Sustainable Development Goals (SDGs) [3].

Wine as an alcoholic beverage when abused could have severe negative consequences not only the individual health and can harm others.

Strongly linked with the cultural and culinary heritage, the environment, the economy and the society of wine regions and countries especially, the viti-vinicultural sector can have strong impact in the 3Ps of sustainability: people, Planet and Profit (triple bottom line). The discussion on 
wine and SDGs should therefore consider the overall role of vine and wines in our societies and the responsible consumption and production throughout the wine value chain.

Broader partnerships between governments, the private sector and civil society are thus required for successful sustainable development agenda and action.

\subsection{Consumer trends and sustainability}

The 2018 Global Consumer Trends [4] published by Wine Intelligence in January of the same year, have identified 12 trends grouped in 5 larger themes: health, Personal, Sustainability, Society, Provide-led. The three trends in Health included the following:

- "Recharge: Products and services that the opportunity to recharge either our bodies, minds or our devices

- Exclude: Removing or reducing natural occurring elements, typically food and drink, with the aim of improving health benefit

- Augment: Adding additional ingredient or dimensions to products and services to "boost" the benefits beyond the original."

The Wine Intelligence's Report [4] also touches upon the theme of Society, recognising a trend named as Respect described as "greater consideration given to the provenance, community, craftmanship, and impact of the products and services we choose".

\subsection{A challenging environment to foster innovation}

Based on the UNWTO findings [1], gastronomic tourism and wine tourism are a growing market, even though more data are needed to understand Wine Tourism trends and growth.

Based on the Wine Intelligence Report [4], consumers are showing increasing interest on healthy and sustainable lifestyles while paying more attention to local societies.

In parallel, as reported in the 2018 Global status report on alcohol and health published by the World Health Organisation (WHO) [3], "the percentage of countries with a written national alcohol policy steadily increased from 2008, and many countries have revised their policies since the Global strategy to reduce the harmful use of alcohol was released." leading to a stricter regulatory environment in many countries.

New trends and technologies, new growing markets and the increasing restrictive policies and regulation, create a challenging environment for the wine business; which could in turn foster innovation and sustainable business models.

\subsection{Wine in moderation programme}

To inspire healthy lifestyles and well-being and contribute to the reduction of alcohol-related harm, the European wine sector came together in 2008 and developed the "Wine in Moderation - Art de Vivre" Programme. Since then, the Wine in Moderation Programme has been growing continuously and has become the Social Responsibility reference programme not only of the European wine value chain but of the international one as well.
Wine in Moderation is a common programme centrally coordinated and implemented nationally, which has the capacity to adapt to local needs while respecting cultural diversity. It builds on scientific evidence, education and self-regulation to organise and empower the entire international wine value chain; raising awareness and knowledge about responsible drinking patterns and moderate wine consumption. The Programme works to encourage responsibility and moderation in the consumption of wine as a cultural and social norm and inspires healthy lifestyles with a view to preventing and reducing alcohol abuse and its related harm. At the same time, it preserves in a sustainable way the cultural, environmental and economic place of wine in our societies.

The programme is guided by the values of Moderation and Responsibility, Diversity and Partnership, Credibility and Dedication and the following principles:

- While the vast majority of consumers enjoy wine in moderation, a minority misuses alcoholic beverage in ways that can be damaging to themselves and that can harm others around them;

- Responsible and moderate consumption patterns of wine can be compatible with a healthy lifestyle;

- Wine is integral to many lifestyles and cultures across the world;

- Wine drinking patterns depend greatly upon local traditions, education, gender, age group and socioeconomic factors; efforts to promote moderation should be tailored to the needs of each population;

- Efforts to promote moderation should be based on sound research, social and cultural aspects;

- The wine value chain brings an invaluable social, cultural, agricultural, environmental and economic contribution to regions and countries;

- All representatives of the wine sector - in every region, and at every step of the value chain - have a role to play in finding the best ways to communicate about the value of moderation and to contribute to the reduction of harm from abusive and hazardous drinking.

The international coordination of the programme is handled by a not-for-profit international association, the WiM Association, also responsible for the accountability and growth of the programme. Action is taken as close as possible to wine professionals and wine consumers. In each country, there are one or more Wine in Moderation National Coordinators that support the planning, coordination, implementation and accountability of the programme in their country with the support of key partners of the wine value chain. Any economic entity that shares the values and principle of Wine in Moderation and wants to contribute to the objectives of the programme is welcome to join as Supporter and take action. In 2018, Wine in Moderation celebrates its 10 years anniversary and represents a mosaic of actions expanding in 16 countries across Europe (11) and South America (5). But it does not stop there, Wine in Moderation actions can be found in far more countries all around the globe. The actions developed by the various actors of the programme include professional training, large multichannel consumer campaigns and edutainment activities in wine fairs and expos. The message on how to appreciate wine is based on the culinary and cultural heritage of wine and is a part of the communication and actions organised to raise 
awareness on the risks related to irresponsible and abusive drinking such as drink and driving.

\section{Considerations for developing sustainable wine tourism}

This article presents several considerations on the design of sustainable wine tourism businesses and proposes good practices to help develop sustainable services.

These considerations and good practices are based on the work developed in the frame of the Wine in Moderation Programme and following discussions with experts.

\subsection{Wine and tourism ecosystems}

The wine sector is a very fragmented and diverse sector, that involves a wide range of businesses of different sizes and structures, ranging from bulk to fine wine producers, from independent wine growers to cooperatives and from boutique wineries to big wine producers and traders.

The structure and organisation of the sector which aims at developing collective action and representing the sector also varies according to the type of wine business, the local/regional/national business culture and other socioeconomic factors.

The wine ecosystem expands and changes significantly if in addition to its core actors (i.e. the wine production and trade) we also consider other actors of the wine value chain, such as wine communicators and educators, hospitality business and professionals, authorities and administration.

In addition to this wealth of actors, the development of wine tourism activities will also gradually involve actors that traditionally belong to the tourism sector/system, further expanding the wine ecosystem. While this expansion will allow much more interaction and learning, it may also lead to more bottleneck effects, resulting in a system that is slower to react to external environment stimulus.

Furthermore, while someone may assume that wine tourism is developed mainly through traditional wine actors, we should consider cases in which a wine region is already a tourist destination and where local actors such as tourist operators, may already be the key actors for the development of the wine tourism offer.

\subsection{Be you, be fit, and do not consider wine only as a product}

When a wine is bottled and branded, its value proposition often goes beyond its functional value (e.g. quality, variety, sensory analysis) [5], and suggests greater value for the customer by creating links with elements such as heritage, culture, land, people, wellness, entertainment, thoughtful production procedure, design/aesthetics, the affiliation and contribution to the local society, sensible appreciation, etc.

If these elements are indeed part of the product's brand and storytelling, the guest will expect to live the story that was promised when visiting the winery. The visit at the winery could therefore be seen as the moment of "truth", it can either destroy the relation with the customer or improve loyalty.
Wine companies that want to develop organised wine tourism activities should carefully consider if tourism fits their organisation's culture, values and strategic objectives and understand how it will help reach their vision. The organisation should identify who is the customer (current and future) of its intended wine tourism services and proceed to a reality check to understand if and how (both organisation and its ecosystem) can address needs and expectations. This will allow it to make a value proposition that will not only create value but also capture it.

Wine tourism activities that are developed without considering the organisation's identity and/or the system's needs may create confusion among the organisation's stakeholders and customers, harming existing relationships.

\subsection{Extend value curve and co-create}

A guided tour of the winery, with a short explanation of the wine's profile and portfolio, followed by a wine tasting paired sometimes with food, can be considered as the usual wine tourism offer. Nonetheless, there are an increasing number of wine businesses that look to offer additional experiences going beyond the product as such but also including the services that allow the customer to live a transformative experience. These experiences can be linked with wine directly, starting in the vineyard with pruning and harvesting experiences to making and bottling your own wine, or from learning how to understand aromas and taste and pair wine with food to wine museums and education. Furthermore, many wineries are also developing activities that are linked with the emotional values that people may attribute to wine such as wellness, entertainment, reduction of anxiety, nostalgia or community feeling/contribution. Activities take the form of spa, yoga classes, horse riding, cooking classes, gourmet/local cuisine, family activities, art events and concerts, to name a few.

This wealth of activities and experiences extend the value proposition and the value curve of a winery and offers them the possibility to diversify from the competition. This extension of services opens the way to new cooperation's and eventually for the co-creation of the new services/experiences. Considering the close link of the winery with the land and local societies, it is also an excellent opportunity to involve local people and actors.

Tasting/selling of local products, hosting events with local artists, developing common experience or extend tours to other farms, or event host a local restaurant in the winery are just a couple of examples.

Assuming that people provide their consent, the digital environment offers the opportunity to access a wealth of data on individual's preferences and behaviours. While a trip may start in front of an internet browser, the idea of this tour may have emerged well before. Knowing who your customer is and having access to behavioural data provides an opportunity to better understand the needs and expectations of the visitor and better shape the value proposition to the customer who could pay more for a better experience or an additional offer. This digital insight could be further expanded by cross-sharing data with other local actors, offering a greater understanding of the future customer; also allowing to co-create experiences, e.g. local festival, that would be much better targeted and 
designed and that would diversify the whole region from the competition.

\section{Integrating responsibility in wine tourism services}

National authorities have developed policies and regulation to prevent, inform and control the risks linked to the harmful use of alcohol. National legislation on alcohol includes setting age limits for the consumption of alcoholic beverage to protect minors from harm and establishing limits in the Blood Alcohol Concentration (BAC) to prevent driving over the influence of alcohol. National legislation can regulate also the consumption of alcohol in the workplace as well licencing systems for selling and serving alcohol and pricing issues.

Guests visiting a winery expect the product they consume and the services they use, to be safe for them and their beloved ones. Regardless of the legislation in place and where the responsibility lies, offering experiences that will allow the guests to responsibly enjoy their wine tourism experience and safely return home, will not only create more value for the guest but will also help the ecosystem capture more value.

\subsection{Facilitate responsibility}

Wineries and wine regions are in rural areas and sometimes quite remoted areas, making them a hard destination to reach. A wine region may involve several wineries and tourist sites that can be situated quite far from one another requiring means of transportation to go from one site to the next. A visitor that is driving to the winery or the wine tourism site will have to preferably avoid drinking or at least make sure that he/she is below the legally established BAC limits.

This necessity often creates a barrier for someone that would like to enjoy a wine experience responsibly and should therefore be a push for wine tourism actors to consider ways to remove the barrier and secure a safe experience for their guests.

Throughout the 10 years of existence of the Wine in Moderation Programme, a number of activities have been developed by the programme actors to support responsible wine experiences.

Organised before, during and after the visit, the activities can take various forms, among which:

- Provide useful information on how to prepare when they plan their visit, offering transportation services and/or providing information for public transport;

- Check ID of participants of tastings and buyers for minimum age;

- Identify and kindly avoid serving people in risk groups (pregnant women and during breastfeeding, intoxicated people, etc.)

- Inform visitors through information material, posters, videos and messaging during the guided tours; on how to appreciate wine and when and who should avoid drinking

- Offer breathalysers to check the Breath Alcohol Concentration (BAC) and sensitize the visitor to the issues related to drink and driving.

- Ask the group to designate a driver that is not drinking and offer a reward for driving the group safely;
- Create a responsible tasting environment by:

- adding spittoons, encouraging people to spit the wine and teach them how to do so;

- regulating the quantity/maximum, number of wines that a visitor can taste;

- providing water and small snacks during tastings;

- For wineries with restaurants, give the opportunity to take home unfinished bottle of wines.

This list of activities is non-exhaustive and does not show the wealth of possibilities out there; evolving along with the wine tourism offer, the partnerships that are set in place at national/regional/local level and the creativity of all the actors involved.

\subsection{Accommodate those that choose not to drink}

In parallel to providing responsible wine experiences to wine consumers, it is also important to consider non-wine drinkers. With the increasing demand in wine tourism, wineries and wine regions will indeed be welcoming a greater number of visitors and new types of guests. The need to accommodate visitors who choose not to drink will arise and lead them to diversify their offer to experience wine culture in new ways that go further than just tasting the wine or visiting the winery.

Whether it is under-legal age individuals, women who are pregnant or breastfeeding, those who are driving, those who chose not to drink for religious beliefs or those who simply do not like the taste; all visitors should indeed have the possibility to experience the cultural and gastronomical experience of wine. A number of activities can be set in place to meet this new demand, for example:

- Educate younger individuals through videos. The cultivation of vines has been part of the agricultural activities since ancient time, why not show them videos to explain the vines universe and its cultivation', educating and informing them about the vine, provides them with more knowledge about the world of the vine, the grape's tastes and the terroirs, helping them understand nature, the circle of life and agriculture;

- Teach the visitors how to smell the aromas and develop their sensitivities with grape juice;

- Organise parallel activities related to the vines and give an agricultural experience;

- Offer non-alcoholic beverages;

- Offer activities linked with their interest as mentioned above that are not linked with wine but with the region, their well-being and entertainment.

This list will also continuously evolve in parallel with the demand in wine tourism, offering new ways to experience wine and wine regions; expanding the reach of wine culture and its related attributes.

\section{Conclusions}

In a growing wine tourism market, wineries and related actors should be fit for purpose, creative and open for partnerships. Adopting a systemic approach, transforming and expanding current business models will be necessary 
to fully capitalise on the potential of more open and sustainable societies and economies. Sustainable wine tourism is an opportunity for growth for the wine value chain, but more research is needed to better understand the need and demand of the wine tourist but also get a better understanding on the role the wine sector can play for the sustainability of our societies and economies.

Wine in Moderation programme provides a framework to foster social responsibility and to enable wineries, wine regions, and wine sector representative bodies to develop responsible wine experiences and inform the consumer about how to enjoy wine responsibly. Higher participation will increase creativity, co-creation and more sustainable business model and actions.

International Organisations such as the International Organisation of Vine and Wine (OIV) and the UNWTO have an important role to play in promoting and motivating partnerships and actions for innovation and sustainable development.

\section{References}

[1] Conclusions 3rd UNWTO Global Conference on Wine Tourism: Wine Tourism as a Tool for Rural Development, United Nation World Tourism Organisation, Government of Republic of Moldova, Chisinau (2018)

[2] UNWTO Georgia Declaration on Wine Tourism, United Nation World Tourism Organisation, Tbilisi (2016)

[3] Global status report on alcohol and health 2018. Geneva: World Health Organization (2018)

[4] Global Consumer Trends 2018, WineiQ, Issue 7 Wine Intelligence (2018)

[5] E. Almquist, J. Senior, N. Bloch, HBR, 46 (2016) 